\title{
CHARACTERISTICS AND DYNAMIC PERFORMANCE OF ELECTRICAL AND HYDRAULIC SERVO-DRIVES
}

\author{
K. Foster*, L. Fenney** \\ *University of Birmingham \\ Birmingham, U.K. \\ ${ }^{* *}$ University of Aston \\ Birmingham, U.K.
}

\begin{abstract}
A brief review of the developments in the design and performance of electric d.c. motors suitable for servo systems is given, and graphs of power rate against angular velocity times the square root of the rotation inertia show how the designs have advanced rapidly in recent years. A comparison is made with the power rates of hydraulic motors, showing the latter to still have significant advantage. A basic, approximate mathematical analysis of the servo-loop for each case is presented, showing the similarities of the block diagram and transfer function for the case of velocity control. Obervations are made about the sensitivity to load disturbance and speed of response. The conclusion is that the hydraulic servo could still be a strong competitor, providing that care is taken with the shaping of the control loop. Overall cost is likely to be in favour of the electric drives.
\end{abstract}

\section{KEYWORDS}

Servo-drives, hydraulic, d.c. electric, rare-earth magnets, power rate.

\section{NOMENCLATURE}

\section{B Flux density}

$\mathrm{H}, \mathrm{H}_{\mathrm{c}} \quad$ Magnetic and critical magnetic field strength

$\mathrm{C}_{d} \quad$ Discharge coefficient

$\mathrm{C}_{\mathrm{p}} \quad$ Coefficient of pressure of servo valve

$\mathrm{C}_{\mathrm{p}}{ }^{\prime} \quad$ Coefficient of additional pressure

feedback

$\mathrm{C}_{\mathrm{x}} \quad$ Coefficient of flow of servo valve

d Displacement / radian

I Current

J Rotational inertia
$\mathrm{K}_{\mathrm{i}}$

$\mathrm{K}_{\mathrm{t}}$

$\mathrm{L}_{\mathrm{a}}$

$\mathrm{N}$

$P, p$

$\mathrm{Q}, \mathrm{q}$

$\mathrm{R}_{\mathrm{a}}$

$S$

$\mathrm{T}$

$\mathrm{V}$

W

$\mathrm{X}$

$\alpha$

$\zeta$

$\rho$

$\theta$

$\tau$

$\omega$

$\omega_{\mathrm{n}}$

$\underline{\text { Subscripts }}$

1 upstream side of hydraulic motor

2 downstream side of motor

e equivalent load, exhaust pressure

f feedback (of velocity)

in input

L load

m motor

s supply
Coefficient of current feedback

Electrical torque constant

Inductance of motor windings

Bulk modulus of hydraulic fluid, also coupling gear ratio

Pressure, small change of pressure

Flow rate, small change of flow

Resistance of motor windings

Laplace transform variable

Torque

Voltage. Also trapped volume in

hydraulic motor

Width of hydraulic valve port

Valve opening

Acceleration

Damping ratio

Fluid density

Angular movement

Time constant

Angular velocity

Natural frequency of servo loop

in

in




\section{INTRODUCTION}

Over the past twenty years considerable development has taken place in control systems for machine drives. Much initial work was done in the field of numerically controlled machine tools, but with the increasing use of the computer for overall control, applications have spread widely throughout industry, including for example, aerospace applications, robot systems and computer integrated manufacture.

Complex, traditional high-speed machines, such as packaging machines, comprise a series of rotary and linear actuators which are used to process a product as it is moved through the machine. Such machines have been designed in the past around a central prime mover which drives each actuator directly, and the independent actions of the actuators are coupled to the central prime mover by appropriate mechanical shafts, gears, cams and linkages. Such designs are inflexible in operation and any design changes are time consuming and costly to implement.

As the speed of machinery has increased, production batches are now finished in shorter times, so that the emphasis is on flexible machinery. The trend is towards synchronised, independent drives because:-

- Digital electronics allows the control of independently-driven machinery sub-systems to be synchronised together and high-speed computers allow the synchronisation to be specified and implemented in software.

- Micro-electronics provide high-speed digital control systems that offer the possibility of improved control algorithms and controllers capable of satisfying tight specifications on performance and accuracy for each autonomous high-speed intermittent drive.

- The use of improved power-semi-conductors and new magnetic materials has produced significant advances in the performance of electrical servodrives.

\section{CHOICE OF DRIVE MOTOR}

For the design of flexible machinery, the selection of appropriate motors and controllers is crucial. In this exercise, two characteristics are particularly important, speed of response and insensitivity to a load disturbance; for example, in a packaging machine, the output load may be relatively small, in a machine-tool, the drive system must be capable of providing accuracy in the face of significant cutting loads.

At one time, hydraulic servos were an automatic choice for many applications, but d.c. electric drives have become almost universally applied to N.C. machines and all but the largest robots. What are the reasons for this? Could improvements be made to hydraulic servos to improve their position in the market?

The considerable improvement in performance of electro-servo motors in recent years has been brought about by improvements in semi-conductor technology and magnetic material, so that:-

a) The use of high current, high-speed switching transistors which are used to produce the switched current waveforms for brushless commutation. The use of feedback transducers mounted on the rotor enables the current waveform to be generated to give maximum motor efficiency with rotor position, while the absence of brushes further enhances commutation efficiency.

b) The torque on a motor is proportional to current times the number of conductors. By optimising this parameter, lower winding inductance is possible, thus improving the response times.

c) Brushless d.c. motors offer considerable improvement in performance. By turning a permanent magnet motor inside out, the electrical windings are cooled more easily and there is also a greater heat capacity. High coercivity, rareearth magnets can tolerate large peak currents without de-magnetisation. In consequence, higher currents can generally be tolerated, and in particular very high currents can be tolerated for short periods of time.

d) In many applications, high currents are required for only short durations, and since high peak currents for short durations are possible, the effective torque to volume ratios of electric motors have significantly increased (as seen later another parameter is more appropriate).

Over the same period, there has not been the same possibility of equivalent improvements to hydraulic servo-drives, since the basic technology has hardly changed.

\section{Permanent Magnet and Brushless DC Motors}

The earliest applications of rare-earth magnets were in conventional direct current (d.c.) motors. Early samarium cobalt magnets were expensive, so the motors were mainly used for aerospace and defence applications, as well as in computer hardware. More recently though, rare-earth magnet d.c. motors have spread into wider use. There are many publications available which describe the construction and operation of d.c. motors. The book by Kenjo and Nagamori (1) includes explanations of d.c. motor and rare-earth magnet characteristics. The structure of a d.c. motor is shown in figure 1 . The rotor carries windings whose many ends terminate at a commutator, which is in effect a switch to control the direction of current in the windings according to rotor position. The stator (the stationary part of the motor) carries the permanent magnets.

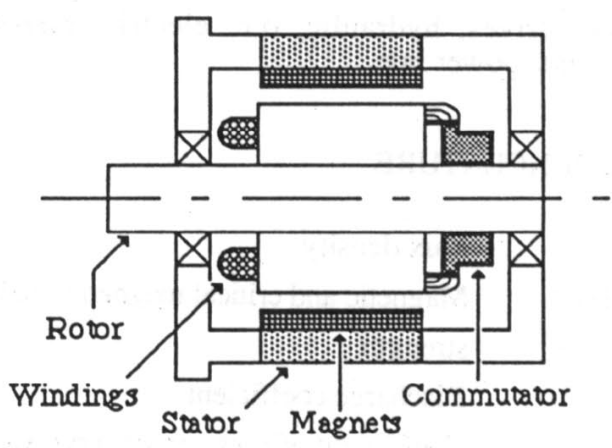

(a) 


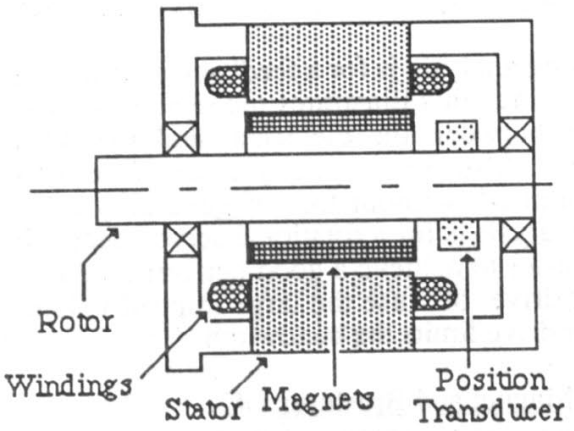

(b)

Figure 1 Servo-Motor Construction

(a) d.c. motor

(b) Brushless d.c. motor.

Since rare-earth magnets are of high coercivity, the rotor designs are different from those of motors with ferrite magnets. The rare-earth magnets have a shorter length along the axis of magnetisation, so they may be oriented radially instead of circumferentially. This has the effect of lowering the winding inductance and increasing the available torque, so direct comparison between the two types of motors are difficult. However, for similarly sized motors with similar inertias, a samarium cobalt motor would generate $150 \%$ torque and $200 \%$ power of a ferrite motor, while the mechanical time constant of the samarium cobalt motor would be approximately $50 \%$ and the electrical time constant approximately $70 \%$ of that of the ferrite motor.

A type of motor which incorporate rare-earth magnets and switched commutation is the brushless d.c. motor, which is shown in figure 1(b). Here the permanent magnets are mounted on the rotor and the electric windings are mounted on the stator. The rotor mounted position transducer provides commutation switching information. Detailed descriptions of brushless d.c. motor operation are contained in Kenjo and Nagamori's book (1) and in the book by Tal (2). Developments in high frequency, high current switching transistors have enabled drive amplifiers to be designed which are capable of supplying very large peak currents to the motor. This capacity is enhanced by the lack of commutation brushes and the efficient cooling characteristics which result from mounting the windings around the perimeter of the motor. So the very large currents can be tolerated by the motor. In addition, the radially oriented, rotor mounted magnets give the motor low inertia and low inductance characteristics.

Direct comparisons between brushless d.c. motors and traditional ferrite magnet d.c. motors can be misleading, because of the differences in their construction and operation. In addition, the improvement in torque performance is not linear through the size range of motors. The basic difference comes from improvements in magnetic materials:-

$\begin{array}{lllll} & \text { Alnico } & \text { Ferrite } & \text { SmCo } & \text { NdFeB } \\ \mathrm{H}_{\mathrm{c}}(\mathrm{kA} / \mathrm{m}) & 55 & 265 & 670 & 890 \\ \mathrm{BH}_{\max }\left(\mathrm{kJ} / \mathrm{m}^{2}\right) & 45 & 28 & 150 & 280\end{array}$

$\mathrm{H}_{c}$ indicates the amount of current that can be tolerated without demagnetising the magnets and $\mathrm{BH}_{\max }$ the force available from a conductor.
Some idea of the differences in performance can be seen in two motors of different design from the same manufacturer. One is a ferrite magnet d.c. motor of inertia $3.7 \times 10^{-5} \mathrm{Kg} . \mathrm{m}^{2}$ and volume $0.00146 \mathrm{~m}^{3}$. This is of similar size to the other, which is a neodymium-iron-boron brushless d.c. motor of inertia $3.4 \times 10^{-5} \mathrm{Kg} \cdot \mathrm{m}^{2}$ and volume $0.00121 \mathrm{~m}^{3}$. The latter generates a continuous torque which is approximately $400 \%$ that of the former, has a mechanical time constant which is only $23 \%$ and an electrical time constant which is $80 \%$ of the former's. Thus the brushless d.c. motor represents a significant increase in performance over traditional ferrite magnet designs.

The types of motor that have been described are all available in high torque, medium speed or medium torque, high speed options, the selection depending on the required power (or torque) and angular velocity. The driveability of servo-drives is primarily dependent on the power rate, $\mathrm{T}_{\mathrm{m}}^{2} / \mathrm{J}_{\mathrm{m}}$ and angular velocity, conveniently coupled with the square root of inertia, i.e. $\omega_{m} \sqrt{J_{m}}$, as explained in the appendix. Figure 2 shows the average driveability ratings of the new types of servo-drives, each type being represented by a line which is a best fit to the scatter produced by plotting the individual motors from the manufacturers' ranges. Each line is labelled with the year in which the range of drives was released for sale. The plot demonstrates the improvements in performance which have been obtained using the new drive technologies. The brushless d.c. motors incorporating rare-earth magnets have the highest driveability ratings per size of any electric drive currently available. Therefore, the drive selection procedure was further developed to concentrate on selecting the optimum brushless d.c. motor for an application.

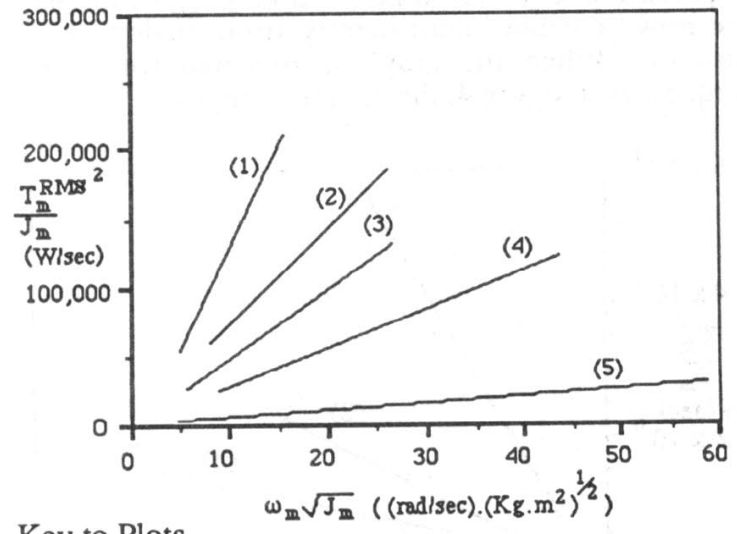

Key to Plots

(1) Neodymium-Iron-Boron brushless d.c. (1987)

(2) Samarium Cobalt brushless d.c. (1985)

(3) Samarium Cobalt brushless d.c. (1986)

(4) Samarium Cobalt d.c. (1983)

(5) Ferrite d.c. (1980)

Figure 2 Comparative Driveability Ratings of Servo-Motors.

\section{Hydraulic Motors}

There are several different types of hydraulic motor used for servo-drives, to a certain extent depending on the application; Bent-axis Piston, In-line Piston, Radial Piston and Gear; Orbital Gear motors being also used for some slow speed applications. An interesting observation arising from plotting the 
characteristics on a graph similar to that of figure 2 is that irrespective of the type, and of some scatter (not shown), the results lie on a straight line, as shown in figure 3. With the particular parameters chosen, power is found by multiplying the square root of the ordinate by the abscissa, so that power comparisons can easily be made. The continuous power range of hydraulic motors is wider than the range of electric motors suitable for servo-drives and extends to much higher power levels The direct competition between the two occurs at the smaller end of the hydraulic range, which are bent axis units originally for aerospace applications.

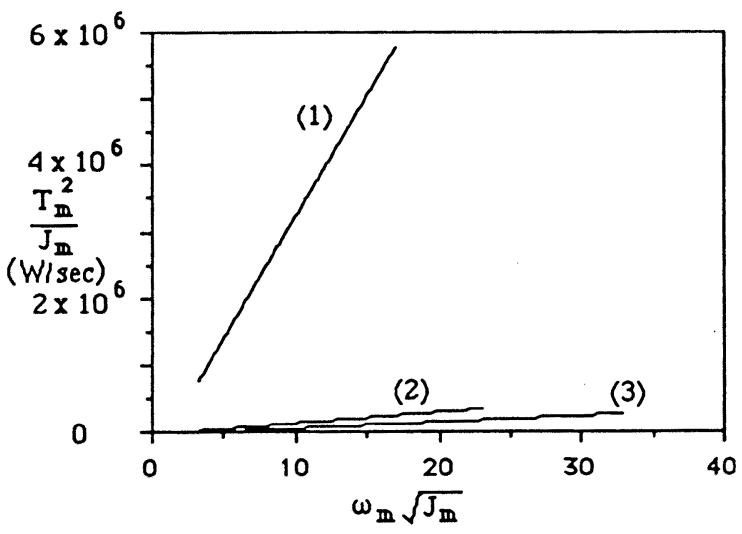

Figure 3 Comparative Continuous Power Rates

(1) Hydraulic

(2) Neodymium-iron-boron brushless d.c.

(3) Samarium Cobalt brushless d.c.

On the face of the results of figure 3, any hydraulic motor is likely to have a significantly faster response than an electric motor of similar power, but such a conclusion would be hasty. In most servo applications high acceleration and deceleration is required for only short times, and very high currents are now possible intermittently from modern d.c. motors. When the graph is repeated for peak torques, as in figure 4 , the picture changes.

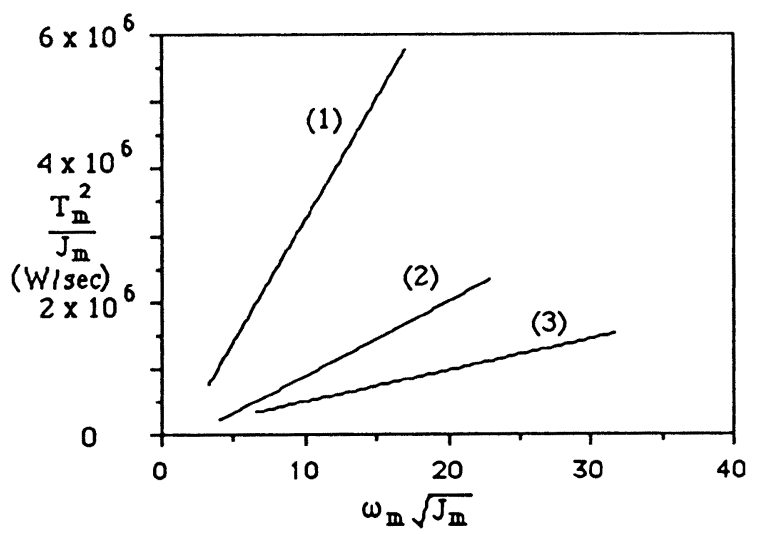

Figure 4 Comparative Power Rates

(1) Hydraulic continuous power rate

(2) $\mathrm{NdFeB}$ brushless d.c. peak power rate

(3) SmCo brushless d.c. peak power rate.

Thus, electric drives are improving fast to be comparable with hydraulic drives in both power and power rate.

\section{BASIC THEORETICAL MODELS FOR DRIVE SERVOS}

The following analysis is for a feedback control loop of velocity, since this illustrates the similarities and differences between the electrical and hydraulic servo-drives. Also for simplicity an amplifier gain has been omitted, without loss of generality. The hydraulic analysis is for a rotational servo, since it is generally easier to achieve a good performance than for a linear drive, because the large trapped volume of the linear drive limits the bandwidth.

Permanent Magnet and Brushless DC

The operating characteristics of permanent magnet and brushless d.c. motors may be represented by similar models. The motor torque $T_{m}$ is proportional to the current in the motor windings and the flux in the magnetic field, i.e.

$$
\mathrm{T}_{\mathrm{m}} \alpha \mathrm{K}_{\mathrm{t}} \mathrm{I}
$$

where $K_{t}$ is the torque constant of the motor. The current is produced in the coils by applying a voltage and is reduced by back e.m.f., i.e.

$$
\mathrm{V}=\left(\mathrm{L}_{\mathrm{a}} \mathrm{S}+\mathrm{R}_{\mathrm{a}}\right) \mathrm{I}+\mathrm{K}_{\mathrm{t}} \omega
$$

where $L_{a}$ and $R_{a}$ are the inductance and resistance of the windings respectively. Assuming that the load consists of a rotational inertia $J_{m}$ and a steady load torque $T_{L}$, the motion of the motor is given by

$$
\mathrm{T}_{\mathrm{m}}=\mathrm{J}_{\mathrm{m}} \mathrm{s} \omega+\mathrm{T}_{\mathrm{L}}
$$

The basic block diagram is shown in figure 5 .

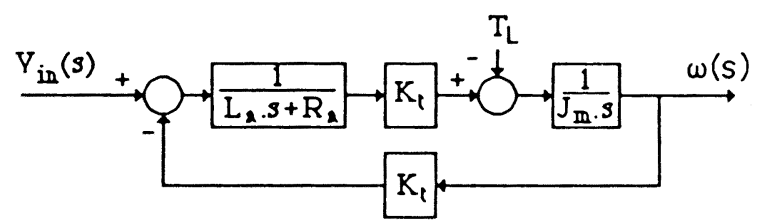

Figure 5 Brushless d.c. Motor Block Diagram.

The motor's response to a disturbance load is given by

$$
\omega(s)=\frac{\left(\mathrm{L}_{\mathrm{a}} \mathrm{s}+\mathrm{R}_{\mathrm{a}}\right)}{\mathrm{J}_{\mathrm{m}} \mathrm{L}_{\mathrm{a}} \mathrm{s}^{2}+\mathrm{J}_{\mathrm{m}} \mathrm{R}_{\mathrm{a}} \mathrm{s}+\mathrm{K}_{\mathrm{t}}^{2}} \mathrm{~T}_{\mathrm{L}}(\mathrm{s})
$$

This can be expressed in terms of the natural frequency $\omega_{n}$, damping ratio $\zeta$ and time constants of the motor

$$
\omega(s)=\frac{K\left(1+\tau_{e} s\right)}{s^{2}+2 \zeta \omega_{n} s+\omega_{n}^{2}} T_{L}(s)
$$

$\zeta$ and $\omega_{\mathrm{n}}$ can be expressed in terms of the motor's electrical time constant $\tau_{\mathrm{e}}$ and a parameter defined as the mechanical time constant $\tau_{\mathrm{m}}$.

$$
\omega_{\mathrm{n}}=\sqrt{\frac{1}{\tau_{\mathrm{e}} \tau_{\mathrm{m}}}} \quad \zeta=\frac{1}{2} \sqrt{\frac{\tau_{\mathrm{m}}}{\tau_{\mathrm{e}}}}
$$


where

$$
\tau_{\mathrm{m}}=\frac{\mathrm{J}_{\mathrm{m}} \mathrm{R}_{\mathrm{a}}}{\mathrm{K}_{\mathrm{t}}^{2}} \quad \tau_{\mathrm{e}}=\frac{\mathrm{L}_{\mathrm{a}}}{\mathrm{R}_{\mathrm{a}}}
$$

The use of rare-earth magnets in the motors, giving small inertias, small inductances and large torque constants, has led to the development of large drives in which $\tau_{\mathrm{e}}$ is very much larger than $\tau_{\mathrm{m}}$. As a result, many large brushless d.c. drives, of rating 6-8 Kw and above, have inherent damping ratios in the range 0.2 to 0.3 , or less. Therefore controllers for brushless motors include current compensation, of coefficient $K_{i}$ to increase the damping ratio, as shown in figure 6.
Also, the flow is taken up by the movement of the motor, and by compressibility of the oil, i.e.

$$
\begin{aligned}
& \mathrm{q}_{1}=\mathrm{d}_{\mathrm{m}} \omega+\frac{\mathrm{V}_{1}}{\mathrm{~N}} \frac{\mathrm{dp}}{\mathrm{dt}} \\
& \mathrm{q}_{2}=\mathrm{d}_{\mathrm{m}} \omega-\frac{\mathrm{V}_{2}}{\mathrm{~N}} \frac{\mathrm{dp_{1 }}}{\mathrm{dt}}
\end{aligned}
$$

where $d_{m}$ is the motor volumetric displacement per radian, $\omega$ is angular velocity, $V_{1}, V_{2}$ are the trapped volumes of oil on the upstream and downstream sides of the motor and $\mathrm{N}$ is the bulk modulus of the fluid. Adding (13) and (14) gives:-

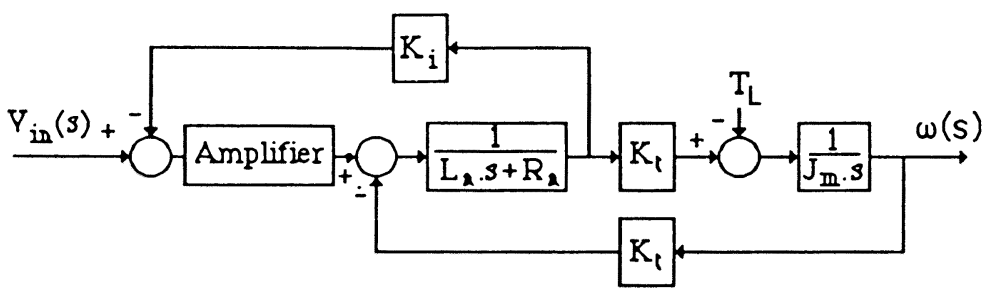

Figure 6 Brushless d.c. Motor with Current Feedback.

In this case, the compensated motor's transfer function is

$$
\omega(s)=\frac{\left(L_{a} s+\left(R_{a}+K_{i}\right)\right) \quad T_{L}(s)}{J_{m} L_{a} s^{2}+J_{m}\left(R_{a}+K_{i}\right) s+K_{t}^{2}}
$$

Thus the current feedback term, $\mathrm{K}_{\mathrm{i}}$ adds to the resistance term in the transfer function. With reference to expressions (6) and (7), increasing $\mathrm{K}_{\mathrm{i}}$ may be seen to increase $\tau_{\mathrm{m}}$ and decrease $\tau_{\mathrm{e}}$ by equal proportions. Thus $\mathrm{K}_{\mathrm{i}}$ may be used to give control of the damping ratio of the motor.

Hydraulic Motor

The flow into a motor from a hydraulic valve is:-

$$
\mathrm{Q}_{1}=\mathrm{C}_{\mathrm{d}} \mathrm{WX} \sqrt{\left(\mathrm{P}_{\mathrm{s}}-\mathrm{P}_{1}\right)_{\mathrm{\rho}}}
$$

where $C_{d}$ is a discharge coefficient, $W$ is the width of the hydraulic valve port, $X$ is the valve opening, $P_{S}$ is the supply pressure, $\mathrm{P}_{1}$ is the pressure on the upstream side of the motor and $\rho$ is the fluid density. A similar expression may be obtained for the flow out of the motor to the exhaust pressure $\mathrm{P}_{\mathrm{e}}$.

This equation is non-linear, and may be linearised by partial differentiation, and, using lower case letters for small changes, thus gives:-

$$
\mathrm{q}_{1}=\mathrm{C}_{\mathrm{x}} \mathrm{x}-\mathrm{C}_{\mathrm{p}} \mathrm{p}_{1}
$$

for flow out of the valve,

$$
\mathrm{q}_{2}=\mathrm{C}_{\mathrm{x}} \mathrm{x}+\mathrm{C}_{\mathrm{p}} \mathrm{p} 2
$$

Adding (10) and (11) gives

$$
\mathrm{q}_{1}+\mathrm{q}_{2}=2 \mathrm{C}_{\mathrm{x}} \mathrm{x}+\mathrm{C}_{\mathrm{p}}\left(\mathrm{p}_{1}-\mathrm{p}_{2}\right)
$$

$$
\mathrm{q}_{1}+\mathrm{q}_{2}=2 \mathrm{~d}_{\mathrm{m}} \omega+\frac{\mathrm{V}}{\mathrm{N}} \mathrm{s}\left(\mathrm{p}_{1}-\mathrm{p}_{2}\right)
$$

The equation for the load is:-

$$
d_{m}\left(p_{1}-p_{2}\right)=J \omega s+T_{L}
$$

The block diagram assuming a feedback from a tachogenerator, becomes:-

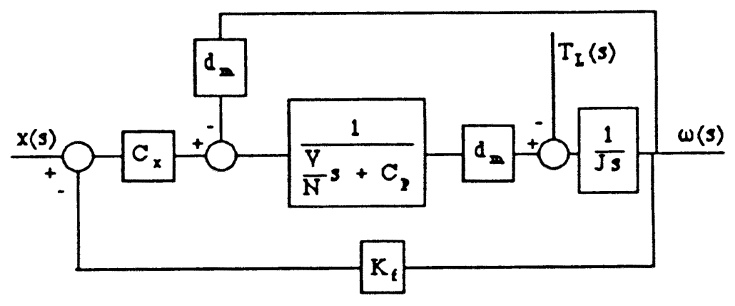

Figure 7 Basic Hydraulic Velocity Servo.

The transfer function between $\omega$ and $T_{L}$ now becomes:-

$$
\omega(s)=\frac{\left(\frac{V}{N} s+C_{p}\right) T_{L}(s)}{\frac{V J}{N} s^{2}+C_{p} J s+2 d_{m}^{2}+2 d_{m} C_{x} K_{f}}
$$

Thus, the transfer functions (8) and (17) shows considerable similarity of form, with $C_{p}$ being similar to $R_{a}$ and $V / N$ being similar to $L_{a}$. In the case of the d.c. motor, a change in torque results in a sharp change in speed before the current builds up against the inductive effect. In the case of the hydraulic motor, there is a sharp change in speed until there has been sufficient flow to build up pressure in the compressible fluid. Thus, the mechanical time constant (rather artificial in the hydraulic case, since $C_{p}$ can be very small) and the hydraulic time constant $\tau_{\mathrm{h}}$ are:- 


$$
\tau_{\mathrm{m}}=\frac{\mathrm{JC}_{\mathrm{p}}}{2 \mathrm{~d}_{\mathrm{m}}^{2}+2 \mathrm{~d}_{\mathrm{m}} \mathrm{C}_{\mathrm{x}} \mathrm{K}_{\mathrm{f}}} \text { and } \quad \tau_{\mathrm{h}}=\frac{\mathrm{V}}{\mathrm{NC}_{\mathrm{p}}}
$$

In both cases the transient response is determined by a quadratic characteristic equation, which, in the hydraulic case has a damping ratio directly proportioned to $C_{p}$, a parameter which can take on values close to zero for small valve openings, a state of affairs which occurs when the servo is used in a position control loop. The equivalent to introducing current feedback is to use pressure feedback of coefficient $\mathrm{C}_{\mathrm{p}}$, i.e.:- a) The dynamic settling time of the hydraulic servo to a change in speed was significantly lower than the equivalent electric motors.

b) The dynamic velocity drop of the hydraulic servo motor due to a load change was significantly greater than that of the electrical machines.

The reason that the hydraulic motor was significantly less stiff in response to a load torque change was entirely due to the low rotor inertia of the hydraulic motor. The comparison was not entirely fair because of the straight-through drive, and had it been possible to use an optimum ratio gearbox, the results

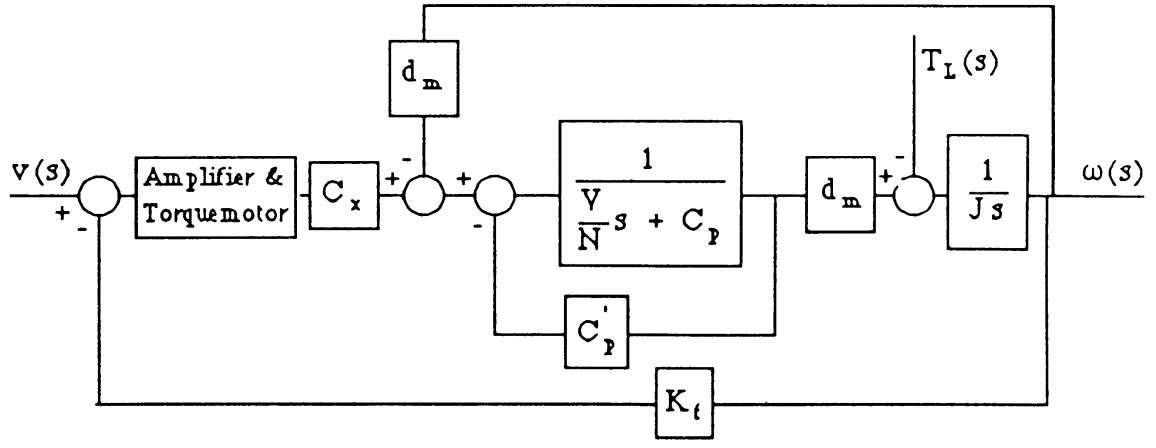

Figure 8 Basic Hydraulic Velocity Servo with Pressure Feedback, Torquemotor and Amplifier

So that the hydraulic time constant :-

$$
\tau_{h}=\frac{V}{N\left(C_{p}+C_{p}^{\prime}\right)}
$$

becomes shorter and the damping ratio greater. An alternative to pressure feedback is acceleration feedback, which is particularly appropriate for linear drives because of being reasonably easy to apply. For more details, see Bell and Pennington (3) and Botting, Eynon and Foster (4). If shaping of the control loop is done in this way, the loop gain can be increased in principle without limit. In practice, the response of the torquemotor and amplifier limits the improvements in loop gain that can be achieved. The response of the amplifier is a similar limiting factor in the electrical case, but the problem is less severe because of the higher basic speed of response.

\section{Comparison of Dynamic Performance.}

In a paper in 1985 (5), Firoozian and Foster examined the dynamic response of various servodrives, both to a step change in the required angular velocity and to a step change in output load. In each case, the servo-loop was optimised by using a leadlag network in the forward path and with the addition of an acceleration term in the feedback path. An integrator was assumed in the forward path also, so that the steady-state error was zero. Thus, it was the dynamic error that formed the basis of comparison in the case of a load disturbance. In the case of machine tool servos, where dynamic errors must be kept to a minimum, this is probably a fair comparison. In other cases, it may be less important.

Because of the application being considered, a straight-through drive was assumed, with no gearbox, so that the optimising of the gearbox ratio was not attempted. The results led to the conclusion that for the optimum-servo-loop:- would have been different in scale, although not different in principle. In the absence of an integrator in the forward path, let us examine the error to a load change.

In the case of the d.c. servo, the steady-state error to a load disturbance is:-

$$
\frac{R_{a}+K_{i}}{K_{t}^{2}}
$$

In the case of the hydraulic servo, if large loop gain can be employed, the steady-state error approximates to:-

$$
\frac{C_{p}+C_{p}^{\prime}}{2 C_{x} K_{f} d_{m}}
$$

Thus for the electical servo, the stiffness is proportional to $\mathrm{K}_{\mathrm{t}}{ }^{2}$, which is very high for a rare earth magnet motor. With a tachogenerator loop added in the hydraulic case, and the need to add a damping term in each case, there need be little to choose between the two systems.

The dynamic error depends to a large extent on the overshoot in the response to a step change in output load torque. This in turn depends on the zero in the transfer function. Another way of seeing the effect is to examine the initial rate of change, which can be found from the application of the initial value theorem of Laplace Transforms. In each case, it can be shown that the initial rate of change is inversely proportional to the effective inertia, which is shown the appendix to be $\mathrm{J}_{\mathrm{e}}=\sqrt{\mathrm{J}_{\mathrm{m}} \mathrm{J}_{\mathrm{L}}}$

Thus it can be seen that the peak value of the error due to a change in load torque varies as a function of the reciprocal of the equivalent load inertia. In 
consequence, as the performance of rare earth magnet motors has improved primarily because of the reduction in rotor inertia, they themselves may suffer a lower dynamic stiffness, and care must be taken again in making the comparisons.

\section{CONCLUSIONS}

1. In the past hydraulic servo-drives have been valuable because of their high power and torque per unit volume. The power rate parameter, i.e. the torque squared divided by the rotational inertia, has a very high value for a given power of motor

2. Whilst rare-earth magnet motors still have a larger volume for a given power than the equivalent hydraulic one, when peak torques are taken into consideration, the power rate of the electric motor is rapidly improving and moving towards the values given by hydraulic motors.

3. Hydraulic servos do not have the advantage of the electrical ones in that the use of modern materials has produced a step change in performance. One part of the system that might possibly benefit from the application of new magnetic materials is the torque motor itself, but whilst this would certainly benefit the bandwidth of the system, the torque motor is only one small part of the hydraulic system, and the effect would be marginal.

4. The electrical time constant of a d.c. drive is now significantly lower than previously, but the hydraulic time constant of the rotational hydraulic servo, unlike that of the linear case, can be kept short because of the small trapped volume.

5. The basic block diagram and transfer function has a similar format in each case, and the treatment to achieve good bandwidth and satisfactory damping have similarities. In practice, achieving a good result is more expensive in the hydraulic case and more awkward because of the necessity of either providing pressure feedback or providing acceleration feedback. In either case, it is probably necessary to use velocity feedback from a tachogenerator to achieve a tight velocity loop, whether or not the system is to be used for position control or for velocity control.

6. The greater use of electrical servos for smaller power applications such as machine tools and industry robots will be influenced also by price and maintenance costs. At the present time, the price of a hydraulic servo is significantly higher than that of the equivalent electrical one, and whereas the cost of the hydraulic systems, because of the precision manufacturing of complex components, is not falling appreciably, the cost of the electrical servo has fallen quite sharply in recent years.

7. Maintenance costs are also significant, but the comparisions are not so straightforward. Providing that attention is paid to cleanliness of the hydraulic system, operation can be trouble free for long periods. Our experience of electrical servos used in high performance, intermittent motion applications has not been entirely good; the driver amplifiers have failed on more than one occasion, and whilst "intelligent" power semi-conductors may provide an answer in the long run, more effort is needed in the design of the driver power amplifiers.

8. The hydraulic servo drive will still keep a strong niche in the high power end of the market, and there is no reason why it should not regain some of the market for middle power applications, providing that complete systems are sold with adequate instrumentation and facilities to provide the correct shaping of the control loop, and hence adequate performance.

\section{ACKNOWLEDGEMENTS}

The authors would like to thank the Science and Engineering Research Council and Molins PLC for support for recent work in this field.

\section{REFERENCES}

1. Kenjo, T. and Nagamori, S. 'Permanent-Magnet and Brushless d.c. Motors'. Clarendon Press, Oxford. 1985

2. Tal, Jacob. 'Motion Control by Microprocessors'. Galil Motion Control Inc. 1984

3. Bell, R. and Pennington, A. 'Active Compensation of Lightly Damped Electrohydraulic Cylinder Drives Using Derivative Signals'. Proc. I.Mech.E., Vol. 184, Pt 1. 1969-70

4. Botting, L.R., Eynon, G.T. and Foster, K. 'The Response of a High-Pressure Pneumatic Servomechanism to Step and Sinewave Inputs'. Proc. I.Mech.E., Vol. 184, Pt 1. 1969-70

5. Firoozian, R. and Foster, K. 'The Choice of a Servo-Motor for a Specific Application'. I.Mech.E., C276/85. 1985

\section{APPENDIX - THE BASIC MOTOR POWER RATE REQUIREMENT}

A representation of a motor driving an angular load is given in figure A.1. The motor, of inertia $\mathrm{J}_{\mathrm{m}}$, drives the inertia load $\mathrm{J}_{\mathrm{L}}$, through a drive ratio $\mathrm{N}$.

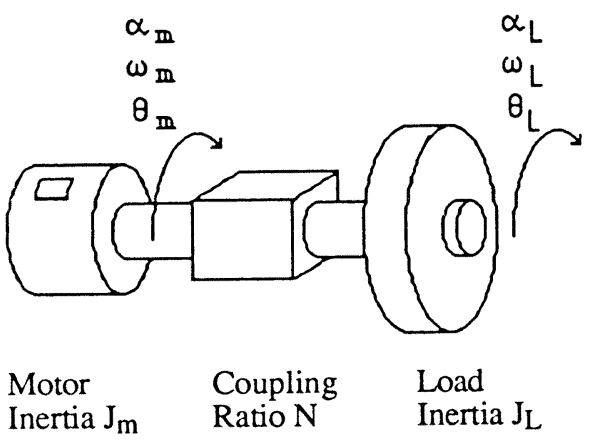

Figure A.1 Angular Motion Drive System.

The torque which is required to be generated by a motor to drive the load $J_{L}$ with an acceleration $\alpha_{L}$ is given by:

$$
T_{m}=N \alpha_{L}\left(J_{m}+\frac{J_{L}}{N^{2}}\right)
$$


Where $T_{m}$ is the required motor torque. The moment of inertia of the drive ratio is assumed to be small, compared to the load, or to be included within the load inertia and the friction torque is assumed to be small, compared to the motor torque. The drive ratio should be selected to minimise the motor torque requirement. This occurs when

$$
\mathrm{N}=\sqrt{\frac{\mathrm{J}_{\mathrm{L}}}{\mathrm{J}_{\mathrm{m}}}}
$$

The torque equation may be combined with the optimum drive ratio equation to give:

$$
\mathrm{T}_{\mathrm{m}}=2 \alpha_{\mathrm{L}} \sqrt{\mathrm{J}_{\mathrm{L}} \mathrm{J}_{\mathrm{m}}}
$$

squaring this equation and rearranging gives the power rate requirement for the drive:

$$
\frac{\mathrm{T}_{\mathrm{m}}^{2}}{\mathrm{~J}_{\mathrm{m}}}=4 \quad \alpha_{\mathrm{L}}^{2} \mathrm{~J}_{\mathrm{L}}
$$

The motor velocity $\omega_{\mathrm{m}}$ is related to the load velocity $\omega_{\mathrm{L}}$ through the drive ratio $\mathrm{N}$ :

$$
\omega_{\mathrm{m}}=\mathrm{N} \omega_{\mathrm{L}}
$$

At the optimum ratio

$$
\omega_{\mathrm{m}} \sqrt{\mathrm{J}_{\mathrm{m}}}=\omega_{\mathrm{L}} \sqrt{\mathrm{J}_{\mathrm{L}}}
$$

Since $J_{L}$ is fixed and $\omega_{L}$ is specified, the two parameters of the motor which may be used to indicate its capacity to drive loads are

$$
\frac{\mathrm{T}_{\mathrm{m}}{ }^{2}}{\mathrm{~J}_{\mathrm{m}}} \quad \text { and } \quad \omega_{\mathrm{m}} \sqrt{\mathrm{J}_{\mathrm{m}}}
$$

